\title{
Serum Trace Elements Profile in Graves' Disease Patients with or without Orbitopathy in Northeast China
}

\author{
Yongping Liu, ${ }^{1}$ Shanshan Liu, ${ }^{2}$ Jinyuan Mao, ${ }^{1}$ Sichen Piao, ${ }^{1}$ Jing Qin, ${ }^{1}$ Shiqiao Peng, \\ Xiaochen Xie, ${ }^{1}$ Haixia Guan $\mathbb{1}^{1},{ }^{1}$ Yushu Li $\left({ }^{\circ},{ }^{1}\right.$ Zhongyan Shan $\mathbb{1}^{1},{ }^{1}$ and Weiping Teng $\left({ }^{1}\right.$ \\ ${ }^{1}$ Department of Endocrinology and Metabolism, Institute of Endocrinology, Liaoning Provincial Key Laboratory of Endocrine Diseases, \\ The First Affiliated Hospital of China Medical University, China Medical University, No. 155, North Nanjing Street, Heping District, \\ Shenyang, China \\ ${ }^{2}$ Department of Emergency, No. 202 Hospital of People's Liberation Army, No. 5, Guangrong Street, Heping District, Shenyang, China
}

Correspondence should be addressed to Haixia Guan; hxguan@vip.126.com and Yushu Li; liyushu@hotmail.com

Received 12 July 2017; Revised 12 November 2017; Accepted 23 November 2017; Published 10 January 2018

Academic Editor: GuoXin Ni

Copyright (C) 2018 Yongping Liu et al. This is an open access article distributed under the Creative Commons Attribution License, which permits unrestricted use, distribution, and reproduction in any medium, provided the original work is properly cited.

\begin{abstract}
Objective. The purpose of the present study was to investigate serum trace elements in Graves' disease (GD) patients with or without orbitopathy in Northeast China. Methods. Patients with newly diagnosed Graves' disease (HyGD) $(n=66)$, GD patients with euthyroid status or subclinical thyroidism after treatment (EUGD) $(n=55)$, GO patients with euthyroid status or subclinical thyroidism after treatment (GO) $(n=57)$, and normal controls (NC) $(n=66)$ were enrolled in this study. Serum trace elements were measured with ICP-MS. Results. Serum selenium (Se) levels in EUGD group (median: 7.53 $\mu \mathrm{g} / \mathrm{dL}$ ), HyGD group (median: $6.76 \mu \mathrm{g} / \mathrm{dL}$ ), and GO group (median: $7.40 \mu \mathrm{g} / \mathrm{dL}$ ) were significantly lower than those in NC group (median: $9.20 \mu \mathrm{g} / \mathrm{dL}$, all $P<$ 0.01). Serum copper $(\mathrm{Cu})$ levels in GO group (median: $95.93 \mu \mathrm{g} / \mathrm{dL}$ ) were significantly lower than those in the NC group (median: $113.59 \mu \mathrm{g} / \mathrm{dL}, P=0.015$ ). After being adjusted for multivariables, thyroid-specific antibodies grade was associated with low Se levels. Hyperthyroidism and thyroid-specific antibodies grade were associated with high Cu levels. In addition, orbitopathy was associated with low $\mathrm{Cu}$ levels. Conclusions. Thyroid autoimmunity was associated with low Se levels. Hyperthyroidism and thyroid autoimmunity may be associated with relatively high serum $\mathrm{Cu}$ levels. Alternatively, ophthalmopathy may be related to low serum $\mathrm{Cu}$ levels.
\end{abstract}

\section{Introduction}

The morbidity of Graves' disease (GD), one of the most common autoimmune thyroid diseases (AITD) [1], has been gradually increasing in China in recent years [2]. This disease is characterized by excessive thyroid hormone, hyperplastic glands, and an increase in stimulating autoantibodies to the TSH receptor (TRAb) [3]. Graves' ophthalmopathy (GO), which potentially changes the patient's appearance, affects vision, impairs the quality of life, and influences social and psychological functions, is the most frequent external thyroid manifestation of GD [4]. However, the etiopathogenesis of GD and GO is not yet completely understood. In addition to genetic and environmental factors, trace elements may play key roles in thyroid physiology and pathology [5].

Trace elements, such as selenium (Se) and copper $(\mathrm{Cu})$, have been reported to be essential cofactors of antioxidant and anti-inflammation system $[6,7]$, which are involved in the production of thyroid hormone [8,9]. Therefore, the trace elements in the body should be present in appropriate concentrations, and abnormal levels of trace metals can develop when the oxidation-antioxidation system fails $[10,11]$. It has been reported that thyroid gland is the organ with the highest levels of trace elements [12]. These elements have potential links with thyroid hormone metabolism, and any deficiency or excess can affect thyroid hormones homeostasis [3, 13-15]. However, it has been reported that thyroid hormone can also affect trace element metabolism [16, 17]. In addition, the effects of microelements are markedly dependent on one another; for instance, low concentrations of selenium may aggravate myxedematous cretinism caused by a deficiency of iodine [18].

However, as far as we know, few studies have examined serum trace elements in patients with thyroid disease in 
China. In this study, we aim to compare the serum levels of trace elements, including Se, vanadium $(\mathrm{V})$, iron $(\mathrm{Fe})$, cobalt $(\mathrm{Co}), \mathrm{Cu}$, zinc $(\mathrm{Zn})$, rubidium $(\mathrm{Rb})$, strontium $(\mathrm{Sr})$, and cesium (Cs), in GD patients with or without orbitopathy in Shenyang, a region with adequate iodine intake in Northeast China.

\section{Materials and Methods}

2.1. Subjects. One hundred and seventy-eight patients, including 55 GD patients without orbitopathy, who were treated with antithyroid drugs alone and achieved a stable euthyroid status or subclinical hyperthyroidism (EUGD group), 66 newly diagnosed hyperthyroid GD patients without GO (HyGD group), and 57 patients with mild-to-moderate GO with an euthyroid state or subclinical hyperthyroidism after treatment with antithyroid drugs (GO group), from the outpatient clinics of the Endocrine Department, the First Hospital of China Medical University, were enrolled in the present study. In addition, 66 healthy controls from the medical examination center (NC group) were enrolled. Across the groups, the subjects were matched for age, gender, and body mass index (BMI). The study was approved by the Ethics Institutional Review Board of China Medical University prior to subject recruitment. All of the participants provided written informed consent prior to enrollment.

Baseline characteristics of all participants, including age, gender, BMI, ethnicity, residence, medical history, previous thyroid treatment, current thyroid treatment, and drug history, were recorded at the interview. The eligibility criteria were as follows: between 18 and 65 years of age and no serious disease (acute infections, stroke, myocardial infarction within 6 months, diabetes, heart disease, renal or hepatic impairment, autoimmune disease, bleeding disorder, or cancer) or pregnancy. None of them have taken multivitamin with trace elements before the study. Additionally, for inclusion in this study, participants were required to comply with the following admission and inclusion criteria.

The admission criteria of HyGD included GD without clinical signs or symptoms of thyroid orbitopathy diagnosed by increased serum concentrations of free thyroxine (FT4) and triiodothyronine (FT3), positive tests for TSH-receptor antibodies (TRAb), increased $\mathrm{I}^{131}$ intake, and thyrotoxicosis associated with diffuse goiter. The patients with a state of euthyroidism or subclinical hyperthyroidism after treatment with antithyroid drugs who once suffered from GD were enrolled in the EUGD group. The inclusion criteria for GO included a diagnosis of mild-to-moderate GO upon examination by an experienced ophthalmologist according to the EUGOGO classification [19], a medical history of GD, and a status of euthyroidism or subclinical hyperthyroidism after treatment with antithyroid drugs. Healthy subjects without chronic and/or infectious diseases were recruited from the medical examination center as controls.

2.2. Methods. Elbow venous blood were collected between $8 \mathrm{AM}$ and $9 \mathrm{AM}$ after fasting for at least 8 hours. The sera were obtained after centrifugation and stored at $-80^{\circ} \mathrm{C}$ prior to analysis.
Serum concentrations of trace elements were measured with inductively coupled plasma mass spectrometry (ICPMS) (Series 7700, Agilent Technologies Inc., California, USA) as previously described [20]. Briefly, blood serum was diluted with nitric acid, and digestion was carried out using the following steps: $1000 \mathrm{~W}\left(0-120^{\circ} \mathrm{C}\right)$ for $15 \mathrm{~min}, 1000 \mathrm{~W}\left(120^{\circ} \mathrm{C}\right)$ for $2 \mathrm{~min}, 1000 \mathrm{~W}\left(120-180^{\circ} \mathrm{C}\right)$ for $15 \mathrm{~min}$, and $1000 \mathrm{~W}\left(180^{\circ} \mathrm{C}\right)$ for $10 \mathrm{~min}$. Next, the appropriate determination parameters for ICP-MS were chosen to detect trace elements. A standards curve and an Internal Standard Mix was used for detection. The coefficient of variation (CV) within the analyses was less than $10 \%$.

Serum thyroid stimulating hormone (TSH), FT3, FT4, thyroperoxidase antibody (TPOAb), and antithyroglobulin antibody (TgAb) were measured using a Chemiluminescent Microparticle Immunoassay (Abbott Laboratories, Abbott Park, IL 60064, USA), and TRAb were measured using an electrochemiluminescence immunoassay with Cobas Eless 601 (Roche Diagnostics). Quality control analyses were performed before, during, and after testing. The reference ranges $(0.35-4.94 \mathrm{mIU} / \mathrm{L}$ for TSH, $2.63-5.70 \mathrm{pmol} / \mathrm{L}$ for FT3, 9.01-19.05 pmol/L for FT4, $0.00-5.61 \mathrm{IU} / \mathrm{mL}$ for TPOAb, $0.00-4.11 \mathrm{IU} / \mathrm{mL}$ for $\mathrm{TgAb}$, and $0.00-1.75 \mathrm{IU} / \mathrm{L}$ for TRAb) were provided by the manufacturer. The intra-assay $\mathrm{CV}$ for TSH were $1.1-5.0 \%$, for FT3 were $1.4-3.4 \%$, for FT4 were 2.3-5.3\%, for TPOAb were $1.8-9.5 \%$, for $\mathrm{TgAb}$ were $1.7-6.6 \%$, and for TRAb were $0.9-7.6 \%$.

2.3. Statistical Analysis. Statistical analysis was carried out using SPSS 22.0 software (SPSS Inc., Chicago, IL, USA) for Windows. Normally distributed data were expressed as the mean \pm standard deviation $(\mathrm{M} \pm \mathrm{SD})$, while data with abnormally distributions were expressed as the median and interquartile intervals (IQRs). One-way analysis of variance (ANOVA) or nonparametric Kruskal-Wallis tests were used to detect differences in the variables across the groups. Spearman correlation coefficients were used to determine correlations between the variables.

Patients were categorized as those with euthyroidism (normal TSH, FT3, and FT4), those with subclinical hyperthyroidism (decreased TSH along with normal FT3 and FT4), and those with hyperthyroidism (decreased TSH along with increased FT3 and FT4). Multivariable ordinal logistic regression models were used to assess the crude and adjusted (controlling for age, gender, and BMI) odds ratios (ORs) and 95\% confidence intervals ( $95 \%$ CIs) for the relationships between hyperthyroidism (dependent variable) and trace elements. We also detected thyroid-specific antibodies (TPOAb and $\mathrm{TgAb})$. According to TPOAb and/or TgAb, participants were also categorized as the negative antibody group (both TPOAb and $\operatorname{TgAb}$ were negative), the weakly positive antibody group (TPOAb and/or TgAb was positive, and both were $<500 \mathrm{IU} / \mathrm{ml}$ ) and the strongly positive antibody group (either $\mathrm{TPOAb}$ or $\mathrm{TgAb}$ was $\geq 500 \mathrm{IU} / \mathrm{ml}$ ). Multivariable ordinal logistic regression models were used to assess the crude and adjusted ORs and 95\% CIs for the relationships between thyroid-specific antibodies grade (dependent variable) and trace elements. In addition, bivariate analysis models were used to test the association between orbitopathy and trace 
TABLE 1: Demographics characteristics and thyroid parameters in different groups.

\begin{tabular}{lcccc}
\hline Variables & NC $(n=66)$ & EUGD $(n=55)$ & HyGD $(n=66)$ & GO $(n=57)$ \\
\hline Age $(\text { years })^{\mathrm{a}}$ & $42.3 \pm 12.6$ & $37.1 \pm 12.6$ & $38.6 \pm 13.1$ & $38.5 \pm 12.1$ \\
Gender $(\mathrm{F} / \mathrm{M})$ & $48 / 18$ & $48 / 7$ & $49 / 17$ & $41 / 16$ \\
BMI $\left(\mathrm{kg} / \mathrm{m}^{2}\right)^{\mathrm{a}}$ & $24.08 \pm 2.84$ & $23.31 \pm 1.56$ & $23.42 \pm 2.18$ & $22.99 \pm 2.76$ \\
TSH $(\mathrm{mIU} / \mathrm{L})^{\mathrm{b}}$ & $1.84(1.16-2.90)$ & $1.45(0.24-2.41)$ & $0.01(0.00-0.02)^{*, \#}$ & $2.19(0.82-3.66)$ \\
FT3 $(\mathrm{pmol} / \mathrm{L})^{\mathrm{b}}$ & $4.46(4.14-4.76)$ & $4.81(4.29-5.24)$ & $14.39(7.55-30.52)^{*, \#}$ & $4.35(3.74-4.83)$ \\
FT4 $(\mathrm{pmol} / \mathrm{L})^{\mathrm{b}}$ & $12.88(11.97-13.81)$ & $12.44(11.15-14.12)$ & $21.89(15.84-35.98)^{*, \#}$ & $12.68(11.11-14.12)$ \\
TPOAb $(\mathrm{IU} / \mathrm{mL})^{\mathrm{b}}$ & $0.38(0.13-1.07)$ & $56.72(8.87-223.00)^{*}$ & $109.75(18.21-447.38)^{*}$ & $19.46(0.13-203.48)^{\dagger}$ \\
TgAb $(\mathrm{IU} / \mathrm{mL})^{\mathrm{b}}$ & $1.24(0.92-3.85)$ & $82.00(27.09-209.70)^{*}$ & $97.01(18.49-367.50)^{*}$ & $4.23(1.22-33.96)^{\#}$ \\
TRAb $(\mathrm{IU} / \mathrm{mL})^{\mathrm{b}}$ & - & $2.05(1.24-6.72)$ & $12.25(5.30-21.02)^{\#}$ & $5.98(1.65-15.36)$ \\
\hline
\end{tabular}

EUGD: subjects with stable euthyroid status or subclinical hyperthyroidism after treatment who used to have Graves' disease; HyGD: newly diagnosed Graves' disease patients; GO: Graves' ophthalmopathy patients with euthyroid state or subclinical hyperthyroidism after treatment with antithyroid drugs; NC: normal controls. ${ }^{a}$ Results are expressed as mean $\pm \mathrm{SD}$. ${ }^{\mathrm{b}}$ Results are expressed as medians (interquartile range); ${ }^{*} P<0.001$ versus NC, ${ }^{\dagger} P<0.01$ versus NC, and ${ }^{\#} P<0.001$ versus EUGD; “"”: did not detect; TSH, thyroid stimulating hormone; FT3, free T3; FT4, free T4; TPOAb, thyroperoxidase antibody; TgAb, antithyroglobulin antibody; TRAb, TSH receptor autoantibody.

elements. A $P$ value $<0.05$ was considered statistically significant, and all tests were two-tailed.

\section{Results}

3.1. Cohort Characterization and Thyroid Parameters. Of the 244 participants, 186 were female, and 58 were male. The characteristics of the different groups are shown in Table 1. No significant differences in age, gender, and BMI across the groups were found. Thyroid parameters (TSH, FT3, and FT4) in the EUGD group were similar to those in the NC group, but the thyroid-specific antibodies (TPOAb and TgAb) were higher than those in the NC group (both $P<0.001$ ). However, compared with the NC and EUGD groups, the HyGD group showed a significant increase in FT3 and FT4 and significant decrease in TSH (all $P<0.001$ ). The HyGD group also exhibited a higher level of TRAb compared with the EUGD group $(P<0.001)$. The GO group exhibited thyroid parameters similar to those in the NC group but TPOAb levels were higher than those in the NC group. In addition, TgAb levels in the GO group were significantly lower than those in the EUGD group. TRAb levels were not significantly different between the GO and EUGD groups.

Spearman correlation analysis of our patients revealed inverse relationships between TSH and TPOAb $(r=-0.337$, $P<0.001)$ and between TSH and TgAb $(r=-0.320, P<$ $0.001)$. Positive correlations were also found between TRAb and FT3 $(r=0.349, P<0.001)$ and between TRAb and FT4 $(r=0.227, P=0.006)$.

3.2. Levels of Trace Elements in GD Patients. As shown in Figure 1, there were significant differences in serum trace elements. Serum Se $(P<0.001), \mathrm{V}(P=0.003)$, and Cs $(P=0.031)$ levels were significantly lower in EUGD group than in NC group, but serum $\mathrm{Co}, \mathrm{Cu}$, and $\mathrm{Sr}$ levels were not (Supplementary Table 1). Next, we compared the levels of serum trace elements in the HyGD and EUGD groups, which exhibit differences in thyroid function. We found that serum $\mathrm{Sr}$ was significantly lower in the HyGD group than in the EUGD group $(P=0.009)$. There were no difference in Se, V, Co, and Cs in the HyGD group compared with the EUGD group. The HyGD group had significantly lower levels of Se $(P<0.001), \mathrm{V}(P<0.001), \mathrm{Sr}(P=0.001)$, and Cs $(P=0.020)$ than the NC group.

3.3. Relationships between Trace Elements and Thyroid Parameters. To demonstrate the associations between serum trace elements concentrations of all the participants, we carried out Spearman correlation analysis on the whole population (Supplementary Table 2). Although the concentration of one trace element may be associated with other elements, no multicollinearity was detected according to the variance inflation factor statistics in multiple linear regression analysis models.

Table 2 shows Spearman correlation analysis between trace elements and thyroid parameters of all the participants. Serum Se was positively correlated with TSH $(r=0.254$, $P<0.001)$ but negatively correlated with FT3 $(r=-0.192$, $P=0.006)$, FT4 $(r=-0.173, P=0.013)$, TPOAb $(r=$ $-0.161, P=0.021)$, and TgAb $(r=-0.237, P=0.001)$. Serum V was negatively correlated with FT3 $(r=-0.313$, $P<0.001)$ and FT4 $(r=-0.165, P=0.018)$. Serum $\mathrm{Cu}$ was positively correlated with FT4 $(r=0.184, P=0.008)$ but inversely correlated with TSH $(r=-0.158, P=0.024)$. Serum Sr was negatively correlated with FT3 $(r=-0.180$, $P=0.010)$ and FT4 $(r=-0.244, P<0.001)$ and positively correlated with TSH $(r=0.191, P=0.006)$. Serum Cs was negatively correlated with $\operatorname{TgAb}(r=-0.155, P=0.026)$.

Multivariable ordinal logistic regression models were used to assess the associations between hyperthyroidism or thyroid-specific antibodies grade with trace elements in the participants. Analyses unadjusted and adjusted for several confounders, including age, gender, and BMI, demonstrated that elevated serum $\mathrm{Cu}$ may be significantly associated with hyperthyroidism $(\mathrm{OR}=1.025,95 \%$ CI: $1.011-1.040$, and $P=0.001$ and $\mathrm{OR}=1.031,95 \%$ CI: $1.015-1.047$, and $P<$ 0.001 , resp.), while lower serum Co and $\mathrm{Rb}$ were found to be associated with hyperthyroidism $(\mathrm{OR}=0.988,95 \% \mathrm{CI}$ : $0.976-0.999$, and $P=0.036$ for $\mathrm{Co}$ and $\mathrm{OR}=0.910,95 \%$ CI: $0.839-0.988$, and $P=0.024$ for $\mathrm{Rb}$ ) in the adjusted 

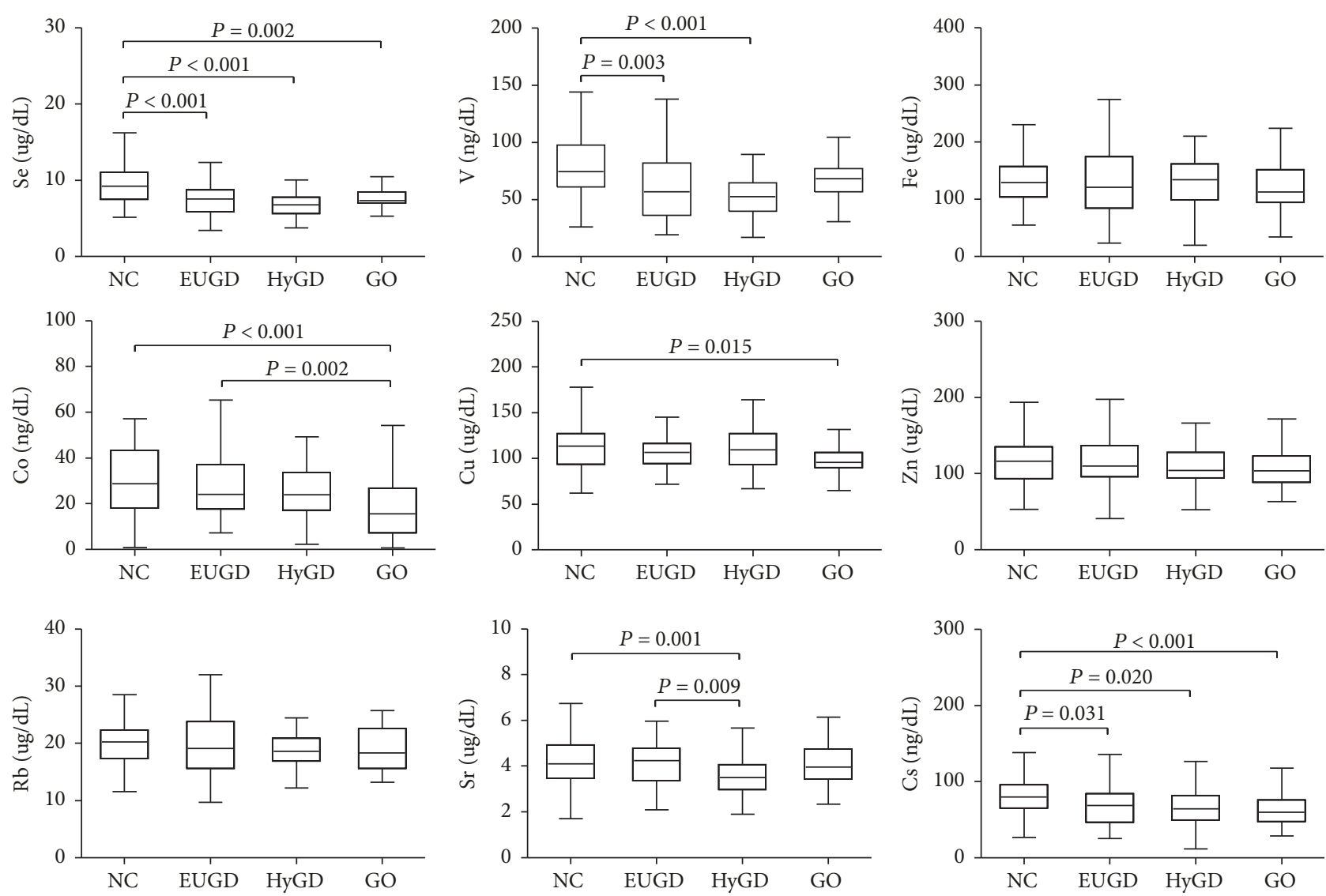

Figure 1: Comparison of trace elements levels. Data were expressed as median and interquartile intervals. Se, selenium; V, vanadium; Fe, iron; Co, cobalt; $\mathrm{Cu}$, copper; Zn, zinc; Rb, rubidium; Sr, strontium; Cs, cesium; NC, normal controls; EUGD, subjects with stable euthyroid status or subclinical hyperthyroidism after treatment who used to be Graves' disease; HyGD, newly diagnosed Graves' disease patients; GO: Graves' ophthalmopathy patients with euthyroid state or subclinical hyperthyroidism after treatment with antithyroid drugs.

TABLE 2: Spearman correlation analysis between trace elements levels and thyroid parameters in all the participants, shown as correlation coefficient ( $P$ value).

\begin{tabular}{lccccc}
\hline Variables & TSH $(P)$ & FT3 $(P)$ & FT4 $(P)$ & TPOAb $(P)$ & TgAb $(P)$ \\
\hline $\mathrm{Se}$ & $0.254(0.000)$ & $-0.192(0.006)$ & $-0.173(0.013)$ & $-0.161(0.021)$ & $-0.237(0.001)$ \\
$\mathrm{V}$ & $0.106(0.129)$ & $-0.313(0.000)$ & $-0.165(0.018)$ & $-0.127(0.069)$ & $-0.112(0.109)$ \\
$\mathrm{Fe}$ & $-0.034(0.632)$ & $0.128(0.066)$ & $-0.010(0.884)$ & $0.036(0.609)$ & $-0.025(0.725)$ \\
$\mathrm{Co}$ & $0.055(0.431)$ & $-0.034(0.631)$ & $-0.048(0.492)$ & $-0.038(0.585)$ & $-0.007(0.926)$ \\
$\mathrm{Cu}$ & $-0.158(0.024)$ & $0.122(0.081)$ & $0.184(0.008)$ & $0.038(0.587)$ & $0.082(0.241)$ \\
$\mathrm{Zn}$ & $0.022(0.758)$ & $0.093(0.184)$ & $-0.037(0.597)$ & $0.098(0.164)$ & $0.129(0.065)$ \\
$\mathrm{Rb}$ & $0.013(0.854)$ & $0.009(0.897)$ & $-0.053(0.447)$ & $-0.062(0.376)$ & $-0.006(0.928)$ \\
$\mathrm{Sr}$ & $0.191(0.006)$ & $-0.180(0.010)$ & $-0.244(0.000)$ & $-0.074(0.290)$ & $-0.124(0.076)$ \\
$\mathrm{Cs}$ & $0.110(0.116)$ & $-0.021(0.767)$ & $-0.061(0.386)$ & $-0.077(0.274)$ & $-0.155(0.026)$ \\
\hline
\end{tabular}

Se, selenium; V, vanadium; Fe, iron; Co, cobalt; $\mathrm{Cu}$, copper; $\mathrm{Zn}$, zinc; Rb, rubidium; Sr, strontium; Cs, cesium; TSH, thyroid stimulating hormone; FT3, free T3; FT4, free T4; TPOAb, thyroperoxidase antibody; TgAb, antithyroglobulin antibody.

model (Table 3). Serum Se were negatively correlated with the levels of thyroid-specific antibodies (TPOAb and TgAb) in both the unadjusted and adjusted models $(\mathrm{OR}=0.828$, 95\% CI: $0.734-0.933$, and $P=0.002$ and $\mathrm{OR}=0.831,95 \%$ CI: 0.736-0.939, and $P=0.003$, resp.). However, serum $\mathrm{Cu}$ may be significantly associated with higher thyroid-specific antibodies grade $(\mathrm{OR}=1.012,95 \% \mathrm{CI}: 1.001-1.023$, and $P=$
0.032 and $\mathrm{OR}=1.016,95 \% \mathrm{CI}: 1.004-1.028$, and $P=0.007$ for the unadjusted and adjusted models, resp.) (Table 4).

3.4. Trace Elements and Orbitopathy. To investigate the levels of trace elements in euthyroid patients with and without orbitopathy, we compared serum trace elements levels in the GO, EUGD, and NC groups. We found that serum Co levels 
TABLE 3: Multivariable ordinal logistic regression to explore the association between hyperthyroidism and trace elements.

\begin{tabular}{lcccccc}
\hline & Unadjusted $\beta(95 \% \mathrm{CI})$ & Unadjusted OR $(95 \% \mathrm{CI})$ & $P$ value & ${\text { Adjusted } \beta(95 \% \mathrm{CI})^{\mathrm{a}}}{\text { Adjusted OR }(95 \% \mathrm{CI})^{\mathrm{a}}} P$ value \\
\hline $\mathrm{Se}$ & $-0.059(-0.206,0.087)$ & $0.942(0.814,1.091)$ & 0.427 & $-0.052(-0.200,0.095)$ & $0.949(0.819,1.100)$ & 0.487 \\
$\mathrm{~V}$ & $0.003(-0.005,0.012)$ & $1.003(0.995,1.011)$ & 0.455 & $0.005(-0.004,0.014)$ & $1.005(0.996,1.014)$ & 0.313 \\
$\mathrm{Fe}$ & $0.005(0.000,0.011)$ & $1.005(1.000,1.011)$ & 0.043 & $0.004(-0.002,0.009)$ & $1.040(0.998,1.009)$ & 0.158 \\
$\mathrm{Co}$ & $-0.012(-0.023,0.000)$ & $0.988(0.977,0.999)$ & 0.042 & $-0.012(-0.024,-0.001)$ & $0.988(0.976,0.999)$ & 0.036 \\
$\mathrm{Cu}$ & $0.025(0.011,0.039)$ & $1.025(1.011,1.040)$ & 0.001 & $0.030(0.015,0.046)$ & $1.031(1.015,1.047)$ & 0.000 \\
$\mathrm{Zn}$ & $-0.004(-0.015,0.007)$ & $0.996(0.985,1.007)$ & 0.454 & $-0.002(-0.014,0.009)$ & $0.998(0.987,1.009)$ & 0.705 \\
$\mathrm{Rb}$ & $-0.075(-0.149,-0.002)$ & $0.927(0.862,0.998)$ & 0.045 & $-0.094(-0.175,-0.012)$ & $0.910(0.839,0.988)$ & 0.024 \\
$\mathrm{Sr}$ & $-0.173(-0.443,0.096)$ & $0.841(0.642,1.101)$ & 0.207 & $-0.287(-0.580,0.005)$ & $0.750(0.560,1.005)$ & 0.054 \\
$\mathrm{Cs}$ & $0.010(-0.003,0.022)$ & $1.010(0.997,1.022)$ & 0.137 & $0.012(-0.001,0.025)$ & $1.012(0.999,1.025)$ & 0.064 \\
\hline
\end{tabular}

${ }^{a}$ Adjusted for age, gender, and BMI; Se, selenium; V, vanadium; Fe, iron; Co, cobalt; Cu, copper; Zn, zinc; Rb, rubidium; Sr, strontium; Cs, cesium; OR: odds ratio; 95\% CI: 95\% confidence interval.

TABLE 4: Multivariable ordinal logistic regression to explore the association between thyroid-specific antibody grade and trace elements.

\begin{tabular}{lcccccc}
\hline & Unadjusted $\beta(95 \% \mathrm{CI})$ & Unadjusted OR $(95 \% \mathrm{CI})$ & $P$ value & ${\text { Adjusted } \beta(95 \% \mathrm{CI})^{\mathrm{a}}}$ & ${\text { Adjusted OR }(95 \% \mathrm{CI})^{\mathrm{a}}} P$ value \\
\hline $\mathrm{Se}$ & $-0.189(-0.310,-0.069)$ & $0.828(0.734,0.933)$ & 0.002 & $-0.185(-0.307,-0.063)$ & $0.831(0.736,0.939)$ & 0.003 \\
$\mathrm{~V}$ & $-0.001(-0.008,0.006)$ & $0.999(0.992,1.006)$ & 0.857 & $0.000(-0.007,0.007)$ & $0.999(0.993,1.007)$ & 0.978 \\
$\mathrm{Fe}$ & $0.003(-0.001,0.007)$ & $1.003(0.999,1.007)$ & 0.146 & $0.002(-0.003,0.006)$ & $1.002(0.997,1.006)$ & 0.447 \\
$\mathrm{Co}$ & $0.001(-0.006,0.008)$ & $1.006(0.994,1.008)$ & 0.858 & $0.000(-0.007,0.008)$ & $1.003(0.993,1.008)$ & 0.928 \\
$\mathrm{Cu}$ & $0.012(0.001,0.023)$ & $1.012(1.001,1.023)$ & 0.032 & $0.016(0.004,0.028)$ & $1.016(1.004,1.028)$ & 0.007 \\
$\mathrm{Zn}$ & $0.002(-0.006,0.010)$ & $1.002(0.994,1.010)$ & 0.589 & $0.001(-0.007,0.009)$ & $1.002(0.993,1.009)$ & 0.801 \\
$\mathrm{Rb}$ & $-0.019(-0.070,0.031)$ & $0.981(0.933,1.032)$ & 0.453 & $-0.025(-0.077,0.026)$ & $0.975(0.926,1.026)$ & 0.331 \\
$\mathrm{Sr}$ & $-0.054(-0.262,0.154)$ & $0.947(0.769,1.066)$ & 0.609 & $-0.062(-0.278,0.154)$ & $0.940(0.757,1.166)$ & 0.573 \\
$\mathrm{Cs}$ & $0.000(-0.010,0.009)$ & $1.000(0.991,1.009)$ & 0.959 & $0.001(-0.009,0.010)$ & $1.001(0.991,1.010)$ & 0.910 \\
\hline
\end{tabular}

${ }^{\mathrm{a}}$ Adjusted for age, gender, and BMI; Se, selenium; V, vanadium; Fe, iron; Co, cobalt; Cu, copper; Zn, zinc; Rb, rubidium; Sr, strontium; Cs, cesium; OR: odds ratio; 95\% CI: 95\% confidence interval.

were significantly lower in the GO group than in the EUGD group $(P=0.002)$, and Se $(P=0.002)$, Co $(P<0.001)$, Cu $(P=0.015)$, and $\mathrm{Cs}(P<0.001)$ tended to be lower in the GO group than in the NC group. However, as shown in Figure 1, there were no significant differences in the levels of serum Fe, $\mathrm{Zn}$, or $\mathrm{Rb}$ between the groups.

A bivariate analysis was performed to examine the association between orbitopathy and trace elements in the patients. We found that $\mathrm{Co}$ and $\mathrm{Cu}$ may negatively be associated with orbitopathy based on unadjusted model and the model adjusted for age, gender, and BMI ( $\mathrm{OR}=0.963,95 \% \mathrm{CI}$ : $0.940-0.987$, and $P=0.003$ and $\mathrm{OR}=0.963,95 \% \mathrm{CI}$ : $0.938-0.988$, and $P=0.004$ for Co; $\mathrm{OR}=0.977,95 \% \mathrm{CI}$ : $0.961-0.993$, and $P=0.004$ and $\mathrm{OR}=0.976,95 \% \mathrm{CI}$ : 0.958-0.995, and $P=0.011$ for $\mathrm{Cu}$, resp.) (Table 5).

\section{Discussion}

To the best of our knowledge, this is the first study to investigate the serum trace elements in patients with GD living in the region with adequate iodine intake in Northeast China.

In the present study, we found that serum Se levels in patients with pathological thyroid conditions, including euthyroid GD patients, newly diagnosed GD patients with hyperthyroidism, and GO patients with euthyroidism, were significantly lower, to varying degrees, than those in normal controls. Serum Se levels in our healthy controls $(9.20 \mu \mathrm{g} / \mathrm{dL}$, $92.0 \mu \mathrm{g} / \mathrm{L}$ ), who resided in areas with marginal soil Se content [21], were similar to the levels found throughout most of Europe, including Denmark (99.8 $\mu \mathrm{g} / \mathrm{L})$ [22] and Greece $(91.8 \mu \mathrm{g} / \mathrm{L})$ [23]. Kucharzewski et al. [24] demonstrated that patients with GD have lower serum Se levels, which is in line with our findings. In the present study, the Se concentrations in the EUGD and HyGD groups were lower than those in the NC group, but there was no difference in Se concentrations between the HyGD group and EUGD group. A retrospective study reported that serum Se levels in GD patients who achieved remission after treatment with antithyroid drugs were higher than those in patients with a relapse, and high serum Se levels $(>120 \mu \mathrm{g} / \mathrm{L})$ were beneficial to the outcome of GD patients [25]. Another study showed that Se supplementation can improve biochemical restoration and that levels of Se were negatively correlated with FT3 in GD [26].

In the present study, we demonstrated that serum Se levels were significantly lower in GO patients than in normal controls, which is in agreement with a study in Germans [27]. Rotondo Dottore et al. [28] found that Se may weaken the effects of oxidative stress, decrease the secretion of proinflammatory cytokines, and reduce the release of hyaluronic acid in orbital fibroblasts from GO patients. A randomized, 
TABLE 5: Bivariate analysis to examine the association between Graves' ophthalmopathy and trace elements levels.

\begin{tabular}{lcccc}
\hline & Unadjusted OR $(95 \% \mathrm{CI})$ & $P$ value & ${\text { Adjusted OR }(95 \% \mathrm{CI})^{\mathrm{a}}}$ & $P$ value \\
\hline $\mathrm{Se}$ & $1.058(0.921-1.214)$ & 0.426 & $1.117(0.940-1.328)$ & $1.008(0.997-1.019)$ \\
$\mathrm{V}$ & $1.000(0.992-1.008)$ & 0.463 & $0.992(0.985-1.000)$ & 0.152 \\
$\mathrm{Fe}$ & $0.996(0.990-1.001)$ & 0.110 & $0.963(0.938-0.988)$ & 0.051 \\
$\mathrm{Co}$ & $0.963(0.940-0.987)$ & 0.003 & $0.976(0.958-0.995)$ & 0.004 \\
$\mathrm{Cu}$ & $0.977(0.961-0.993)$ & 0.004 & $1.000(0.988-1.012)$ & 0.956 \\
$\mathrm{Zn}$ & $0.993(0.983-1.003)$ & 0.186 & $1.004(0.941-1.070)$ & 0.910 \\
$\mathrm{Rb}$ & $0.996(0.947-1.047)$ & 0.874 & $1.167(0.876-1.553)$ & 0.291 \\
$\mathrm{Sr}$ & $1.061(0.831-1.355)$ & 0.633 & $0.994(0.978-1.010)$ & 0.450 \\
$\mathrm{Cs}$ & $0.991(0.979-1.003)$ & 0.147 &
\end{tabular}

${ }^{a}$ Adjusted for age, gender, and BMI; Se, selenium; V, vanadium; Fe, iron; Co, cobalt; Cu, copper; Zn, zinc; Rb, rubidium; Sr, strontium; Cs, cesium; OR: odds ratio; 95\% CI: 95\% confidence interval.

double-blind, placebo-controlled trial conducted by the European Group on Graves' Orbitopathy (EUGOGO) found that supplementation with Se in patients with mild Graves' orbitopathy may improve the quality of life and retard the development of the disease [29], although the serum Se concentrations were not measured in this study. These results support the hypothesis that GD and GO patients are at risk of low serum Se levels; but further research is needed to identify the exact effect and its mechanism of action.

A high correlation between low serum Se status and a high degree of thyroid autoimmunity has been reported in several publications [30,31], and our result is consistent with these findings. An epidemiological study conducted by $\mathrm{Wu}$ et al. [31] in two regions of China that were defined as having adequate Se content and low Se content indicated that higher serum Se levels were significantly associated with lower risk of autoimmune thyroiditis. A recent systematic review conducted by Wichman et al. [32] reported that Se supplementation may reduce thyroid-specific antibodies levels. Consequently, low serum Se is a trigger or a risk factor for abnormal thyroid function.

One study in a general US population conducted by Jain, based on the data from the 2011 to 2012 US National Health and Nutrition Examination Survey (NHANES), demonstrated that serum $\mathrm{Cu}$ was positively associated with FT4 and TT4 in men [33]. Consistent with this, our results indicated that $\mathrm{Cu}$ levels were slightly higher in patients with GD than in patients with EUGD $(P=0.261)$ and were positively associated with FT4 levels. In addition, we also found hyperthyroidism may be associated with higher $\mathrm{Cu}$ levels. There are several publications reporting that $\mathrm{Cu}$ metabolism was affected by hyperthyroidism $[34,35]$. A study in animals conducted by Mittag et al. [36] found significant increase of $\mathrm{Cu}$ levels when treated with thyroid hormone. The decline expression of competing intracellular $\mathrm{Cu}$-binding proteins and enhancive synthesis and export of hepatic ceruloplasmin, the major $\mathrm{Cu}$-carrying protein, could explain this phenomenon.

There are conflicting reports on the relationship between serum $\mathrm{Cu}$ and thyroid autoimmunity. Erdal et al. [37] found no difference between Hashimoto's thyroiditis (HT) and normal controls. But a recent study conducted by Rasic-Milutinovic et al. [38] detected the higher blood
$\mathrm{Cu}$ concentration in HT patients compared with normal controls. In the present study, we found higher $\mathrm{Cu}$ levels may be related with thyroid autoimmunity according to multivariable ordinal logistic regression. It was reported that the destruction of serum $\mathrm{Cu}$ homeostasis may contribute to the oxidative stress state in HT patients [38]. In addition, it has been detected that the activation of Fas/FasL (Fas ligand) could contribute to the pathogenesis of AITD. The accumulation of $\mathrm{Cu}$ in the liver may also promote the translation of FasL in patients with Wilson's disease and activate the system of Fas/FasL to subsequently induce apoptosis in liver cells [39]. It is reasonable to propose the same pathogenesis in thyroid autoimmunity, but further studies are needed to clarify.

Unlike serum Se, serum $\mathrm{Cu}$ in patients with $\mathrm{GO}$ is rarely studied. Here, we found that GO patients are at risk of a low serum $\mathrm{Cu}$ levels. $\mathrm{Cu}$ is integrated in the active center of superoxide dismutase (SOD), the essential antioxidant enzyme for the removal of the oxygen free radical and the prevention of oxidative stress damage. A study in an animal model suggested that the generation and accumulation of reactive oxygen species in the thyroid may disrupt the antioxidation system [40], and oxygen free radicals may simultaneously cause the proliferation of orbital fibrosis [41]. Kaur et al. [42] reported significantly reduced SOD levels in the plasma of hyperthyroid patients with GO, and there was no improvement even after treatment with antithyroid drugs. However, SOD activity was not assessed in the present study; therefore, further research is needed to determine the exact mechanism.

In the present study, we also detected the serum levels of several elements, including $\mathrm{V}, \mathrm{Fe}, \mathrm{Co}, \mathrm{Zn}, \mathrm{Sr}$, and $\mathrm{Cs}$. Although little is known about the biological function of these elements in thyroid diseases, the present study demonstrated the unique elements profile of those patients.

Our study had some limitations. One major limitation was its cross-sectional design. As a result of this design, we failed to observe any changes in trace elements in the same patient with different thyroid function and thyroid autoimmunity. Another limitation is that we did not measure serum and urinary iodine levels, although all of the participants resided in an area with adequate iodine levels [43]. 
In conclusion, trace elements, which are involved in various physiological and pathological processes, are closely related to the thyroid gland. The present study demonstrated lower serum Se levels in patients with GD, with or without ophthalmopathy. A relatively high level of serum $\mathrm{Cu}$ may be associated with hyperthyroidism. Our findings are also the first to indicate that a relatively low level of serum $\mathrm{Cu}$ may be associated with ophthalmopathy. However, further research must be conducted to elucidate the regulation of $\mathrm{Cu}$ homeostasis in thyroid diseases.

\section{Conflicts of Interest}

The authors declare that they have no conflicts of interest.

\section{Acknowledgments}

The authors would like to thank Fengchao Han, Director of Pharmacy, Shenyang Center for Drug Adverse Reaction and Medical Devices Adverse Events Monitoring, Shenyang, Liaoning Province, for his help with ICP-MS for the detection of trace elements. This study was supported by the Clinical Medicine Research Special Funds of Chinese Medical Association (Grant no. 12010070267).

\section{Supplementary Materials}

Supplementary Table 1: serum trace elements concentrations in different groups. Supplementary Table 2: Spearman correlation analysis among serum concentrations of the different trace elements in all the participants. (Supplementary Materials)

\section{References}

[1] A. P. Weetman, "Autoimmune thyroid disease," Autoimmunity, vol. 37, no. 4, pp. 337-340, 2004.

[2] F. Yang, Z. Shan, X. Teng et al., "Chronic iodine excess does not increase the incidence of hyperthyroidism: A propective community-based epidemiological survey in China," European Journal of Endocrinology, vol. 156, no. 4, pp. 403-408, 2007.

[3] L. Schomburg, "Selenium, selenoproteins and the thyroid gland: Interactions in health and disease," Nature Reviews Endocrinology, vol. 8, no. 3, pp. 160-171, 2012.

[4] K. A. Ponto, S. Merkesdal, G. Hommel, S. Pitz, N. Pfeiffer, and G. J. Kahaly, "Public health relevance of graves' orbitopathy," The Journal of Clinical Endocrinology \& Metabolism, vol. 98, no. 1, pp. 145-152, 2013.

[5] L. H. Duntas, "Environmental factors and thyroid autoimmunity," Annales d'Endocrinologie, vol. 72, no. 2, pp. 108-113, 2011.

[6] M. P. Rayman, "The importance of selenium to human health," The Lancet, vol. 356, no. 9225, pp. 233-241, 2000.

[7] N. Maouche, D. Meskine, B. Alamir, and E.-A. Koceir, "Trace elements profile is associated with insulin resistance syndrome and oxidative damage in thyroid disorders: Manganese and selenium interest in Algerian participants with dysthyroidism," Journal of Trace Elements in Medicine and Biology, vol. 32, pp. 112-121, 2015.
[8] U. Schweizer, J. Chiu, and J. Köhrle, "Peroxides and peroxidedegrading enzymes in the thyroid," Antioxidants \& Redox Signaling, vol. 10, no. 9, pp. 1577-1592, 2008.

[9] L. H. Duntas and S. Benvenga, "Selenium: an element for life," Endocrine Journal, vol. 48, no. 3, pp. 756-775, 2015.

[10] P. Ozturk, E. Belge Kurutas, and A. Ataseven, "Copper/zinc and copper/selenium ratios, and oxidative stress as biochemical markers in recurrent aphthous stomatitis," Journal of Trace Elements in Medicine and Biology, vol. 27, no. 4, pp. 312-316, 2013.

[11] V. Bacic-Vrca, F. Skreb, I. Cepelak, L. Mayer, Z. Kusic, and B. Petres, "The effect of antioxidant supplementation on superoxide dismutase activity, $\mathrm{Cu}$ and $\mathrm{Zn}$ levels, and total antioxidant status in erythrocytes of patients with Graves' disease," Clinical Chemistry and Laboratory Medicine, vol. 43, no. 4, pp. 383-388, 2005.

[12] A. Cayir, H. Doneray, N. Kurt et al., "Thyroid functions and trace elements in pediatric patients with exogenous obesity," Biological Trace Element Research, vol. 157, no. 2, pp. 95-100, 2014.

[13] T. Miyamoto, A. Sakurai, and L. J. Degroot, "Effects of zinc and other divalent metals on deoxyribonucleic acid binding and hormone-binding activity of human alpha 1 thyroid hormone receptor expressed in Escherichia coli," Endocrinology, vol. 129, no. 6, pp. 3027-3033, 1991.

[14] A. Betsy, M. P. Binitha, and S. Sarita, "Zinc deficiency associated with hypothyroidism: An overlooked cause of severe alopecia," International Journal of Trichology, vol. 5, no. 1, pp. 40-42, 2013.

[15] M. Kucharzewski, J. Braziewicz, U. Majewska, and S. Góźdź, "Copper, zinc, and selenium in whole blood and thyroid tissue of people with various thyroid diseases," Biological Trace Element Research, vol. 93, no. 1-3, pp. 9-18, 2003.

[16] K. Aihara, Y. Nishi, S. Hatano et al., "Zinc, copper, manganese, and selenium metabolism in thyroid disease," American Journal of Clinical Nutrition, vol. 40, no. 1, pp. 26-35, 1984.

[17] A. Kralik, K. Eder, and M. Kirchgessner, "Influence of zinc and selenium deficiency on parameters relating to thyroid hormone metabolism," Hormone and Metabolic Research, vol. 28, no. 5, pp. 223-226, 1996.

[18] M. B. Zimmermann and J. Köhrle, "The impact of iron and selenium deficiencies on iodine and thyroid metabolism: biochemistry and relevance to public health," Thyroid, vol. 12, no. 10, pp. 867-878, 2002.

[19] L. Bartalena, L. Baldeschi, A. Dickinson et al., "Consensus statement of the European Group on Graves' orbitopathy (EUGOGO) on management of GO," European Journal of Endocrinology, vol. 158, no. 3, pp. 273-285, 2008.

[20] X. Hu, R. Wang, Z. Shan et al., "Perinatal Iron DeficiencyInduced Hypothyroxinemia Impairs Early Brain Development Regardless of Normal Iron Levels in the Neonatal Brain," Thyroid, vol. 26, no. 7, pp. 891-900, 2016.

[21] S. Li, T. Xiao, and B. Zheng, "Medical geology of arsenic, selenium and thallium in China," Science of the Total Environment, vol. 421-422, pp. 31-40, 2012.

[22] I. Bülow Pedersen, N. Knudsen, A. Carlé et al., "Serum selenium is low in newly diagnosed Graves' disease: A population-based study," Clinical Endocrinology, vol. 79, no. 4, pp. 584-590, 2013.

[23] S. Letsiou, T. Nomikos, D. Panagiotakos et al., "Serum total selenium status in Greek adults and its relation to age. the ATTICA study cohort," Biological Trace Element Research, vol. 128 , no. 1, pp. 8-17, 2009. 
[24] M. Kucharzewski, J. Braziewicz, U. Majewska, and S. Gózdz, "Concentration of selenium in the whole blood and the thyroid tissue of patients with various thyroid diseases," Biological Trace Element Research, vol. 88, no. 1, pp. 25-30, 2002.

[25] T. Wertenbruch, H. S. Willenberg, C. Sagert et al., "Serum selenium levels in patients with remission and relapse of Graves' disease," Medicinal Chemistry, vol. 3, no. 3, pp. 281-284, 2007.

[26] J. Calissendorff, E. Mikulski, E. H. Larsen, and M. Möller, "A prospective investigation of graves' disease and selenium: Thyroid hormones, auto-antibodies and self-rated symptoms," European Thyroid Journal, vol. 4, no. 2, pp. 93-98, 2015.

[27] N. Dehina, P. J. Hofmann, T. Behrends, A. Eckstein, and L. Schomburg, "Lack of association between selenium status and disease severity and activity in patients with graves' ophthalmopathy," European Thyroid Journal, vol. 5, no. 1, pp. 57-64, 2016.

[28] G. Rotondo Dottore, M. Leo, G. Casini et al., "Antioxidant Actions of Selenium in Orbital Fibroblasts: A Basis for the Effects of Selenium in Graves' Orbitopathy," Thyroid, vol. 27, no. 2, pp. 271-278, 2017.

[29] C. Marcocci, G. J. Kahaly, G. E. Krassas et al., "Selenium and the course of mild Graves' orbitopathy," The New England Journal of Medicine, vol. 364, no. 20, pp. 1920-1931, 2011.

[30] H. Derumeaux, P. Valeix, K. Castetbon et al., "Association of selenium with thyroid volume and echostructure in 35- to 60year-old French adults," European Journal of Endocrinology, vol. 148, no. 3, pp. 309-315, 2003.

[31] Q. Wu, M. P. Rayman, H. Lv et al., "Low population selenium status is associated with increased prevalence of thyroid disease," The Journal of Clinical Endocrinology \& Metabolism, vol. 100, no. 11, pp. 4037-4047, 2015.

[32] J. Wichman, K. H. Winther, S. J. Bonnema, and L. Hegedüs, "Selenium Supplementation Significantly Reduces Thyroid Autoantibody Levels in Patients with Chronic Autoimmune Thyroiditis: A Systematic Review and Meta-Analysis," Thyroid, vol. 26, no. 12, pp. 1681-1692, 2016.

[33] R. B. Jain, "Thyroid function and serum copper, selenium, and zinc in general U.S. population," Biological Trace Element Research, vol. 159, no. 1-3, pp. 87-98, 2014.

[34] F. Zhang, N. Liu, X. Wang, L. Zhu, and Z. Chai, "Study of trace elements in blood of thyroid disorder subjects before and after 131I Therapy," Biological Trace Element Research, vol. 97, no. 2, pp. 125-133, 2004.

[35] A. K. Baltaci, R. Mogulkoc, and M. Belviranli, "L-thyroxineinduced hyperthyroidism affects elements and zinc in rats," Bratislava Medical Journal, vol. 114, no. 3, pp. 125-128, 2013.

[36] J. Mittag, T. Behrends, K. Nordström, J. Anselmo, B. Vennström, and L. Schomburg, "Serum copper as a novel biomarker for resistance to thyroid hormone," Biochemical Journal, vol. 443, no. 1, pp. 103-109, 2012.

[37] M. Erdal, M. Sahin, A. Hasimi, G. Uckaya, M. Kutlu, and K. Saglam, "Trace element levels in hashimoto thyroiditis patients with subclinical hypothyroidism," Biological Trace Element Research, vol. 123, no. 1-3, pp. 1-7, 2008.

[38] Z. Rasic-Milutinovic, D. Jovanovic, G. Bogdanovic, J. Trifunovic, and J. Mutic, "Potential Influence of Selenium, Copper, Zinc and Cadmium on L-Thyroxine Substitution in Patients with Hashimoto Thyroiditis and Hypothyroidism," Experimental and Clinical Endocrinology \& Diabetes, vol. 125, no. 2, pp. 79-85, 2017.

[39] S. Strand, W. J. Hofmann, A. Grambihler et al., "Hepatic failure and liver cell damage in acute Wilson's disease involve CD95
(APO-1/Fas) mediated apoptosis," Nature Medicine, vol. 4, no. 5, pp. 588-593, 1998.

[40] V. Fernandez, X. Barrientos, K. Kipreos, A. Valenzuela, and L. A. Videla, "Superoxide radical generation, NADPH oxidase activity, and cytochrome P-450 content of rat liver microsomal fractions in an experimental hyperthyroid state: relation to lipid peroxidation," Endocrinology, vol. 117, no. 2, pp. 496-501, 1985.

[41] H. B. Burch, S. Lahiri, R. S. Bahn, and S. Barnes, "Superoxide radical production stimulates retroocular fibroblast proliferation in graves' ophthalmopathy," Experimental Eye Research, vol. 65, no. 2, pp. 311-316, 1997.

[42] A. Kaur, S. Pandey, S. Kumar, A. A. Mehdi, and A. Mishra, "Oxidative stress profile in graves' ophthalmopathy in Indian patients," Orbit, vol. 29, no. 2, pp. 97-101, 2010.

[43] Z. Shan, L. Chen, X. Lian et al., "Iodine status and prevalence of thyroid disorders after introduction of mandatory universal salt iodization for 16 years in China: A cross-sectional study in 10 cities," Thyroid, vol. 26, no. 8, pp. 1125-1130, 2016. 


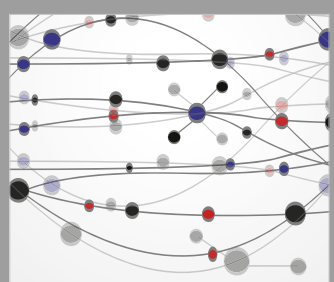

The Scientific World Journal
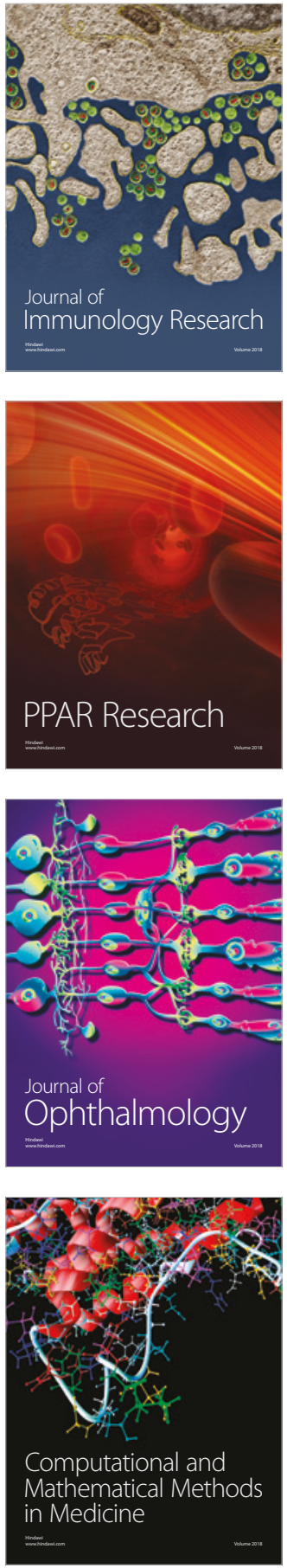

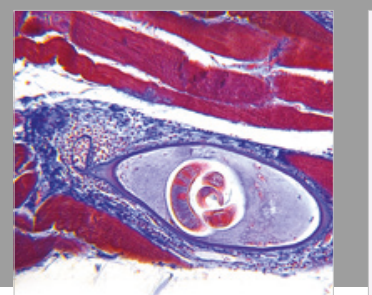

Gastroenterology Research and Practice

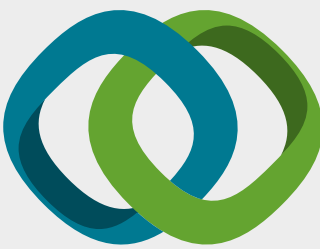

\section{Hindawi}

Submit your manuscripts at

www.hindawi.com
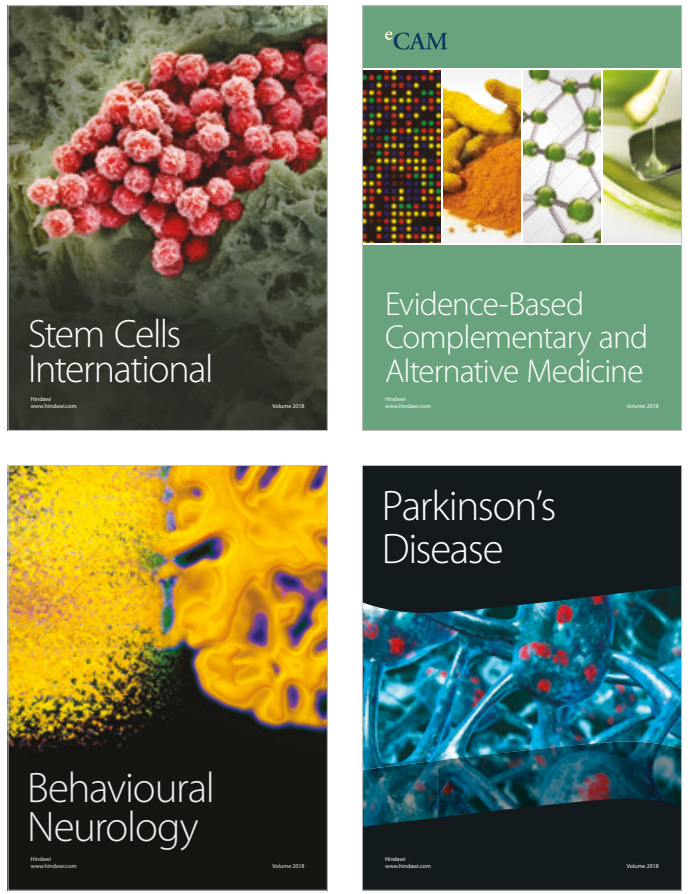

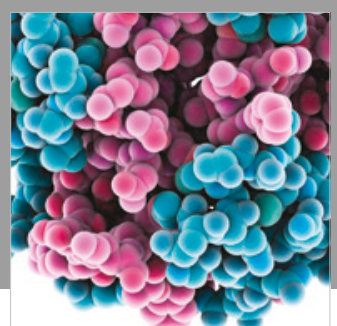

ournal of

Diabetes Research

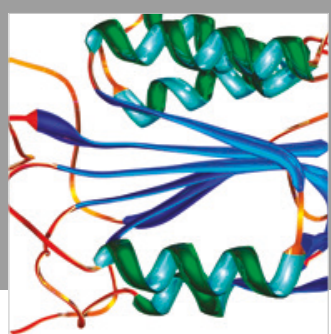

Disease Markers
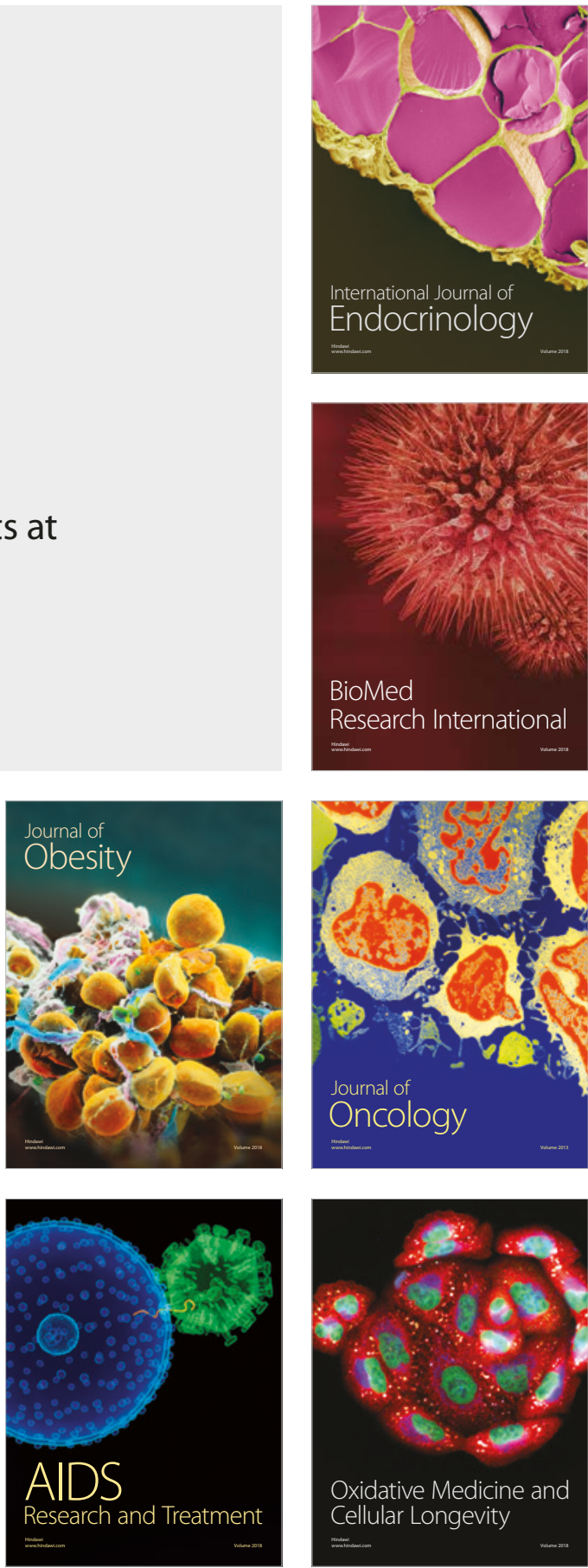